\title{
La responsabilidad cuasicontractual en Ecuador: ¿una determinación contractual o extracontractual?
}

\section{Quasi-contractual civil liability in Ecuador: a contractual or non-contractual determination?}

Marcela Natalia Cervantes Armijos*

Recibido / Received: 9/10/2020

Aceptado / Accepted: 30/03/2021

DOI: https://doi.org/10.18272/ulr.v8i1.2143

\section{Citación:}

Cervantes Armijos, M.N. «La responsabilidad cuasicontractual en Ecuador: ¿̨una determinación contractual o extracontractual?». USFQ Law Review, Vol 8, no 1, mayo de 2021, pp. 29 - 48, doi: $10.18272 /$ ulr.v8i1.2143 


\section{RESUMEN}

La normativa ecuatoriana ha obedecido a la clasificación binaria tradicional de la responsabilidad civil, regulando la contractual y extracontractual. Ante esto, ha prevalecido un incansable debate respecto del ámbito de aplicación de cada una. Esta discusión, tanto doctrinal como jurisprudencial, deja un vacío legal en cuanto al régimen aplicable a la hipótesis de daños derivados del incumplimiento de obligaciones cuasicontractuales. El presente artículo tiene como objeto de estudio la delimitación del alcance de la responsabilidad contractual y aquiliana bajo el ordenamiento jurídico ecuatoriano, por medio de un análisis sistémico e integral de la norma. Asimismo, analiza la aplicación de la doctrina mayoritaria y predominante sobre la responsabilidad cuasicontractual bajo el Código Civil, donde se concluye que la responsabilidad cuasicontractual en Ecuador debe regirse bajo las reglas del régimen contractual.

\section{Palabras Clave}

Responsabilidad civil; contractual; extracontractual; cuasicontractual; obligaciones

\section{Abstract}

Ecuadorian law has obeyed the traditional binary classification of civil liability, regulating contractual and extra-contractual liability. There has been a tireless debate regarding the scope of application of each one. This discussion, both doctrinal and jurisprudential, leaves a legal vacuum as to the applicable regime to the hypothesis of damages derived from the breach of quasi-contractual obligations. The purpose of this article is to study the delimitation of the scope of contractual and tort liability under the Ecuadorian legal system, through a systemic and comprehensive analysis of the norm. It also analyzes the application of the majority and predominant doctrine on quasi-contractual liability under the Civil Code, where it is concluded that quasi-contractual liability in Ecuador should be governed under the rules of the contractual regime.

\section{KeYWORDS}

Civil liability; non-contractual; contractual; quasi contractual; obligations 


\section{INTRODUCCIÓN}

El Código Civil ecuatoriano (en adelante CC) regula la institución de la responsabilidad civil obedeciendo a la clásica distinción entre la responsabilidad contractual y extracontractual. Sin embargo, quedan dudas sobre el régimen jurídico aplicable a la responsabilidad derivada del incumplimiento de obligaciones cuasicontractuales en el ordenamiento jurídico ecuatoriano. Esto se debe a que, tanto el CC, como la jurisprudencia nacional, no delimitan el alcance de cada uno de los regímenes mencionados y, sobre esto, cuál de ellos resulta aplicable a la responsabilidad emanada de una relación cuasicontractual.

En la actualidad se discute el ámbito de aplicación de la responsabilidad civil contractual, respecto de la cual no queda claro si: (i) es aquella que se deriva del incumplimiento de un vínculo obligacional previo o, (ii) necesariamente, del incumplimiento de una obligación contractual. En cuanto a la responsabilidad aquiliana, se debate si: (i) es aquella que se deriva únicamente de la comisión de delitos o cuasidelitos civiles o, (ii) si se trata de un régimen residual al de la responsabilidad contractual, es decir, abarcando el incumplimiento de cualquier obligación no convencional. Estas interrogantes conllevan a la existencia de un vacío normativo y una pregunta de sustancial importancia: ¿qué tipo de responsabilidad procede ante el incumplimiento de obligaciones cuasicontractuales?

Si bien el cuasicontrato, como fuente de obligaciones, es una categoría jurídica sumamente cuestionada en el derecho moderno $-\mathrm{y}$ ha sido materia de arduas críticas por parte de doctrinarios como Valencia Zea- ${ }^{1}$ en Ecuador esta cotidiana figura continúa vigente, y, por lo mismo, resulta importante determinar el régimen de responsabilidad que respecto de ella resulta aplicable. En consecuencia, el presente trabajo tiene como propósito la determinación del alcance de la responsabilidad que procede ante el incumplimiento de obligaciones emanadas de un cuasicontrato en el sistema jurídico ecuatoriano. Esto se realizará a través de una metodología sistémica; mediante la cual se revisarán las distintas teorías que ilustran el alcance de la responsabilidad contractual y extracontractual mencionadas anteriormente, a nivel doctrinal y jurisprudencial, así como los fundamentos y elementos propios de cada una. Lo anterior constituirá una guía para analizar e interpretar integralmente los indicios que el CC ecuatoriano manifiesta en su estructura, redacción y coherencia; a propósito de la responsabilidad aplicable a las relaciones cuasicontractuales. El estudio de lo expuesto responderá, entonces, a la pregunta:

1 Arturo Valencia Zea manifiesta en su libro Derecho Civil. De las Obligaciones que "[l]a expresión cuasicontrato debe desecharse”, pues para él esta figura no merece ser diferenciada y categorizada como una fuente de obligaciones distinta por el solo hecho de carecer de un acuerdo de voluntades. 
¿cuál es la regulación aplicable en materia de responsabilidad civil ante daños resultantes del incumplimiento cuasicontractual?

\section{LA RESPONSABILIDAD CIVIL EN EL SISTEMA JURÍDICO ECUATORIANO}

El CC ecuatoriano prescribe tres principales cuasicontratos en el artículo 2185: la agencia oficiosa, el pago de lo no debido y la comunidad. ${ }^{2}$ La nomenclatura de "principales" ${ }^{3}$ en el artículo eiusdem, deja en manifiesto que existen otros cuasicontratos innominados dispersos en nuestra legislación. ${ }^{4}$ No obstante, se analizarán únicamente los cuasicontratos nominados. Aquellos se encuentran regulados en el Libro IV, Título XXXII, del artículo 2184 hasta el 2213.

El CC regula la división clásica de la responsabilidad civil: contractual y extracontractual o aquiliana. El Título XXXIII del Libro IV respecto a los delitos y cuasidelitos, regula la responsabilidad extracontractual, el cual refleja la intención del legislador de la restricción de este tipo de responsabilidad a la ocurrencia de delitos y cuasidelitos. A su vez, el Título XII del Libro IV, respecto del efecto de las obligaciones, regula la responsabilidad contractual, evidenciando la amplitud de la aplicación de este régimen, sin delimitarlo explícitamente a las relaciones contractuales, sino obligacionales en sentido genérico.

También, la jurisprudencia ecuatoriana se ha manifestado sobre el alcance de ambos regímenes de responsabilidad. Así ocurrió en los casos Tito Yépez Jiménez c. World Vacation Wortion S.A. y Time Sharing S.A. ${ }^{5}$ y en Victor Andrade Carrillo c. Willian Javier Saltos y Jackita Montenegro, ${ }^{6}$ donde la ex Corte Suprema de Justicia opinó sobre el tema en cuestión, dando luces respecto al criterio predominante sobre la materia en Ecuador. De igual forma sucedió posteriormente en una sentencia de la Corte Nacional de Justicia en el caso María Josefa Cabrera Delgado c. Rosa Imelda Cabrera y Benjamin Molina Tapia. ${ }^{7}$ Lo expresado en cada fallo será analizado con posterioridad, con el objeto de develar la cuestionable posición de la jurisprudencia nacional en cuanto a la división clásica de la responsabilidad.

2 Artículo 2185, Código Civil [CC], R.O. Suplemento 46, de 24 de junio de 2005, reformado por última vez el 08 de julio de 2019.

3 Art. 2185, CC: "Hay tres principales cuasicontratos: la agencia oficiosa, el pago de lo no debido, y la comunidad".

4 A saber, el depósito necesario en manos de un incapaz es un ejemplo de cuasicontrato innominado: "Art. 2143.- El depósito necesario de que se hace cargo un adulto que no tiene la libre administración de sus bienes, pero que está en su sana razón, constituye un cuasicontrato que obliga al depositario, sin la autorización de su representante legal".

5 Juicio No. 142-2001, Corte Suprema de Justicia, Primera Sala de lo Civil y Mercantil, 24 de septiembre de 2001, párr. 11.

6 Juicio No. 56-2004, Corte Suprema de Justicia, Primera Sala de lo Civil y Mercantil, 25 de febrero de 2005, párr. 5.

7 Juicio No. 17711-2014-0540, Corte Nacional de Justicia, Sala de lo Civil y Mercantil, 26 de noviembre de 2014, párr. 6.3. 


\section{TeOrías de RESPONSABILIDAD}

La institución jurídica de la responsabilidad tiene, al menos, tres distintas formas de clasificación: (i) por su objeto: civil y penal; (ii) por el rol que asume la culpa como elemento de la responsabilidad: subjetiva y objetiva; y (iii) por su fundamento: contractual y extracontractual. Esta última constituye una de las clasificaciones más importantes de la responsabilidad, por ello en el presente trabajo se analizarán y cuestionarán las teorías que han explicado esta categorización. De esa manera, se revisarán las doctrinas que delimitan el alcance de cada una de ellas, estudiando a fondo principalmente, el elemento generador de la responsabilidad contractual y la extracontractual. Lo anterior se observará para determinar cuál de ellos resulta aplicable para el incumplimiento cuasicontractual.

Teniendo en cuenta que existen diversas teorías sobre el alcance de la dualidad de regímenes de responsabilidad, varios doctrinarios y juristas han expuesto sus criterios al respecto. Primero, en relación con la discusión acerca de la procedencia de la responsabilidad extracontractual. Por un lado, Joaquín Llambías ${ }^{8}$ y René Abeliuk ${ }^{9}$ comparten un criterio similar, pues para ellos esta surge ante la comisión de delitos y cuasidelitos civiles. Por otro lado, Arturo Vodanovic ${ }^{10}$ y Hernán Corral Talciani, ${ }^{11}$ justifican su existencia en un fundamento general: la ausencia de una obligación previa como presupuesto de este régimen.

Segundo, sobre las teorías de la responsabilidad contractual, Abeliuk, ${ }^{12}$ Vodanovic ${ }^{13}$ y Corral Talciani ${ }^{14}$ concuerdan en que el presupuesto para la procedencia de esta institución es la presencia de un vínculo obligacional previo. Sin embargo, Llambías discrepa de esta aseveración y su interpretación resulta más restrictiva, ya que, para dar paso a este tipo de responsabilidad, él considera necesaria una relación contractual específicamente.

Es con base en esta distinción -caracterizada por el origen de cada tipo de responsabilidad- donde cabe la discusión acerca de la regulación que rige a las obligaciones cuasicontractuales. Al respecto, pocos han sido los autores que han abordado las teorías de responsabilidad que incluyan al incumplimiento cuasicontractual dentro de alguna de las categorías jurídicas mencionadas. No obstante, entre ellos, se estudiará la tesis expuesta por Corral Talciani referente al derecho común en materia de responsabilidad aplicable a las obligaciones

\footnotetext{
Jorge Joaquín Llambías, Tratado de Derecho Civil, Parte General, Tomo II (Buenos Aires: Editorial Perrot, 1997), 62.

René Abeliuk Manasevich, Las Obligaciones. Tomo I (Chile: Editorial jurídica de Chile, 2009), 124.

Arturo Vodanovic Haklicka, Curso de Derecho Civil, Tomo III (Chile: Nascimento, 2006), 196.

Hernán Corral Talciani, Lecciones de Responsabilidad Civil Extracontractual (Chile: Thomson Reuters, 2003). 25.

Abeliuk, Las Obligaciones, 124.

Vodanovic, Curso de Derecho Civil, 196.

Talciani, Lecciones de Responsabilidad Civil, 25.
} 
no convencionales, en la cual, efectivamente, la regla general es la aplicación del régimen contractual y, por ende, la excepción es la aplicación de las normas de la responsabilidad aquiliana. En ese sentido, Arturo Alessandri Rodríguez ${ }^{15}$ y Luis Díez-Picazo, ${ }^{16}$ estudiando el derecho chileno y español respectivamente; junto con Velásquez Posada ${ }^{17}$ analizando la normativa colombiana; llegan a la misma conclusión respecto de la responsabilidad aplicable a las obligaciones cuasicontractuales, a pesar de usar criterios y razonamientos distintos. Finalmente, también se analizará la doctrina francesa explicada por Henri Mazeaud ${ }^{18}$ con base en la reglamentación del CC francés, quien tiene un argumento contrario a la tesis expuesta por Corral Talciani.

\section{Los cuasicontratos en el Código Civil y su naturaleza JURÍDICA}

\subsection{Definición del Cuasicontrato}

Diversos ordenamientos jurídicos han optado por la división clásica de las fuentes de las obligaciones, tomando como ejemplo lo establecido por los glosadores medievales, enumerando como tales al: contrato, cuasicontrato, delito, cuasidelito civil y, posteriormente, agregando la ley a esta clasificación. ${ }^{19}$ Siguiendo esta línea, el artículo 2184 del CC ecuatoriano establece las diversas fuentes de obligaciones en nuestro sistema, definiendo al cuasicontrato como: "[l] as obligaciones que se contraen sin convención, nacen, o de la ley, o del hecho voluntario de una de las partes [...] si el hecho del que nacen es lícito, constituye un cuasicontrato". ${ }^{20}$

Varios doctrinarios tanto nacionales como internacionales, a saber: Luis Parraguez, Luis Claro Solar y Ramón Meza Barros; han emitido sus propias definiciones del cuasicontrato, así como también, críticas y comentarios acerca de esta figura, en la que se cuestiona y resalta el papel del consentimiento, intención o voluntad, porque "[...] en los cuasicontratos resulta obligada una persona sin que su voluntad haya intervenido o se haya incluso manifestado en contrario". ${ }^{21}$ En ese sentido, Parraguez define al cuasicontrato como: "un hecho voluntario y lícito del hombre, que genera obligaciones independientemente de la intención de su autor", ${ }^{22}$ resaltando el factor de la ausencia de intención. Claro Solar, por su parte, considera que el cuasicontrato es:

15 Arturo Alessandri Rodríguez, De la responsabilidad extracontractual en el Derecho Civil chileno (Santiago de Chile: Editorial Jurídica de Chile, 2005), 35

16 Luis Díez-Picazo, Derecho de Daños (España: Civitas, 1999), 264.

17 Obdulio Velásquez Posada, Responsabilidad Civil Extracontractual (Bogotá: Editorial Temis, 2009), 49.

18 Henri Mazeaud, "Responsabilité delictuelle et responsabilité contractuelle", Revue Trimestrielle de Droit Civil (1929), 551.

19 Abeliuk, Las Obligaciones, 104.

20 Artículo 2184, CC.

21 Abeliuk, Las Obligaciones, 109.

22 Luis Parraguez Ruiz, Manual de Derecho Civil Ecuatoriano. Libro Cuarto: Teoría General de las Obligaciones (Ecuador: Universidad Técnica Particular de Loja, 2000), 76. 
"[e]l hecho voluntario de una persona, que lo obliga respecto de otra persona, o que puede obligar a ésta sin que haya prestado su consentimiento". ${ }^{23}$ Finalmente, Meza Barros define a esta fuente como un hecho lícito no convencional que genera obligaciones. ${ }^{24}$ Todas estas definiciones, aluden a uno de los principales elementos diferenciadores de esta figura con el contrato: la carencia de un acuerdo de voluntades. Por último, cabe también destacar la licitud como presupuesto del cuasicontrato. Aquello lo diferencia de los delitos y cuasidelitos civiles.

\subsection{LOS CUASICONTRATOS NOMINADOS EN ECUADOR}

El primer cuasicontrato materia del presente análisis es la agencia oficiosa. El artículo 2186 del CC también lo denomina gestión de negocios ajenos, mediante el cual, el que administra sin mandato los negocios de alguna persona, se obliga para con esta y la obliga en ciertos casos. ${ }^{25} \mathrm{~A}$ lo largo del parágrafo $1^{\text {o }}$ del Título XXXII se regulan las obligaciones derivadas de esta relación, entre el agente y el interesado. El segundo cuasicontrato por estudiarse es el pago de lo no debido. El artículo 2195 prescribe la obligación de restitución para quien recibe un pago que no se le debía. ${ }^{26}$ Por último, la comunidad se regula en el parágrafo $3^{\circ}$ del Título XXXII y se define en el artículo 2204 de la siguiente manera: "[l] a comunidad de una cosa universal o singular, entre dos o más personas, sin que ninguna de ellas haya contratado sociedad o celebrado otra convención relativa a la misma cosa, es una especie de cuasicontrato". ${ }^{27}$

\subsection{Hipótesis DE INCUMPLIMIENTO CUASICONTRACTUAL}

El propósito de este enunciado es enmarcar al lector en las posibles hipótesis, que a modo de ejemplo servirán como base para el entendimiento de los supuestos en los que procedería la responsabilidad civil cuasicontractual. Los cuasicontratos, a pesar de no referir un acuerdo de voluntades previo, presuponen una relación obligacional entre sujetos. Dentro de este vínculo jurídico creado como consecuencia de un hecho voluntario de una de las partes, se generan obligaciones que deben ser cumplidas. Sin embargo, puede ocurrir el caso en el que, al igual que en los contratos, esas obligaciones no se cumplan. Precisamente en ese punto se circunscribe el presente estudio, por lo que a continuación se enunciarán algunos casos de incumplimiento cuasicontractual.

\footnotetext{
Luis Claro Solar, Explicaciones de Derecho Civil chileno y comparado (Santiago de Chile: Nascimento, 1937), 521.

Ramón Meza Barros, Manual de Derecho Civil de las Obligaciones (Chile: Editorial jurídica de Chile, 2007), 12.

Artículo 2186, CC.

6 Id. Artículo 2195.

27 Id. Artículo 2204.
} 
El CC prescribe que las obligaciones del agente dentro de la agencia oficiosa son las mismas del mandatario. ${ }^{28}$ Por ende, el agente oficioso queda generalmente obligado a emplear en su gestión los cuidados de un buen padre de familia. ${ }^{29}$ De igual manera, deberá encargarse de todas las dependencias del negocio y continuar con la gestión hasta que el interesado pueda tomarla o encargarla a otro. ${ }^{30}$ Las obligaciones emanadas de la agencia oficiosa no recaen únicamente sobre el agente, sino también sobre el interesado. En ese sentido, el interesado está obligado al reembolso para con el agente de las expensas útiles y necesarias. Así, puede ocurrir que tanto el interesado como el agente, incumplan con estas obligaciones generando dańos en detrimento del otro, siendo procedente la aplicación del régimen de responsabilidad civil.

En el pago de lo no debido, la obligación prescrita para quien se le ha pagado por error y se ha probado que no se le debía dicho pago, es la restitución de este. ${ }^{31}$ De esa forma, puede suceder que esta obligación sea incumplida y genere perjuicios en el marco de la relación jurídica que ya ha sido creada por ocurrencia del error. Así, el parágrafo $2^{\circ}$ del Título XXXII prescribe la hipótesis de una demanda por la restitución —el cumplimiento de la obligación—entre quien pagó por error y quien recibió ese pago.

En el cuasicontrato de comunidad, cada comunero está obligado a pagar las deudas de la cosa común, contribuir en las obras, realizar las reparaciones de la comunidad proporcionalmente a su cuota y restituir a la comunidad lo que retira de ella. ${ }^{32}$ De ese modo, en este vínculo obligacional que existe entre cada comunero, puede ocurrir el incumplimiento de cualquiera de estas obligaciones, de modo que, al generar daños, podría derivar en un contexto de responsabilidad civil.

\section{UN CONTRASTE ENTRE LA RESPONSABILIDAD CIVIL}

\section{CONTRACTUAL Y EXTRACONTRACTUAL}

\subsection{FundAMENTOS DE DISTINCIÓN}

Existen elementos y características que permiten diferenciar la responsabilidad civil contractual de la extracontractual; sin embargo, se observarán las principales a continuación.

La mora es uno de los fundamentales diferenciadores entre ambas responsabilidades. Espinoza se refiere a la mora como: "[u]na situación jurídica, siendo el 
efecto legal automático del pedido de cumplimiento ante el retardo imputable al deudor o acreedor".$^{33}$ Por esta razón, la procedencia de este presupuesto en la responsabilidad contractual tiene sentido, pues desde la constitución en mora, el deudor responde por los perjuicios sufridos por el incumplimiento de la obligación. ${ }^{34}$ De esa manera, para Hinestrosa la mora resulta "indispensable desde el punto de vista de la responsabilidad y, particularmente, del derecho a indemnización", ${ }^{35}$ por cuanto la constitución en mora sirve como punto referencial para determinar el momento desde el que se debe la indemnización. Esto no ocurre en la responsabilidad aquiliana, donde la constitución en mora no procede, porque se debe la indemnización desde la ocurrencia del mismo hecho dañoso ${ }^{36}$ y debido a la ausencia de una obligación previa entre la víctima y el deudor.

Asimismo, la culpa es un factor sustancial de la responsabilidad civil que diferencia a la extracontractual de la contractual, ya que, respecto de esta última, la gradación es trascendental por su naturaleza. Al respecto, Meza Barros señala que "[l] a culpa contractual admite gradaciones: puede ser grave, leve o levísima. La culpa extracontractual no admite gradaciones [...]”. ${ }^{37}$

La gradación de la culpa varía dependiendo del beneficio obtenido por las partes respecto de la utilidad y beneficio de las obligaciones de por medio:

Art. 1563.- El deudor no es responsable sino de la culpa lata en los contratos que por su naturaleza sólo son útiles al acreedor; es responsable de la leve en los contratos que se hacen para beneficio recíproco de las partes; y de la levísima, en los contratos en que el deudor es el único que reporta beneficio. ${ }^{38}$

Al contrario, en la responsabilidad extracontractual, no es procedente la gradación de culpas ya que "[...] la culpa por más leve que sea da lugar a la responsabilidad extracontractual". ${ }^{39}$

Además, la culpa se presume en la responsabilidad contractual. De esa manera, el artículo 1563 del CC prescribe, "[...] la prueba de la diligencia o cuidado incumbe al que ha debido emplearlo". ${ }^{40}$ Mientras que, en la responsabilidad aquiliana, la regla general obedece a que la culpa del deudor debe ser probada por la víctima. ${ }^{41}$

33 Juan Espinoza Espinoza, "La mora", Themis Revista de Derecho (2015): 231, http://revistas.pucp.edu.pe/index.php/themis/ article/view/15596.

34 Artículo 1573, CC.

35 Fernando Hinestrosa, "Notas sobre la responsabilidad por incumplimiento de las obligaciones", Revista de Derecho Privado No. 36. (2018): 13, https://doi.org/10.18601/01234366.n36.01.

36 Talciani, Lecciones de Responsabilidad Civil, 29.

37 Meza Barros, Manual de Derecho Civil, 123.

38 Artículo 1563, CC.

39 Abeliuk, Las Obligaciones, 132.

40 Artículo 1563, CC.

41 Javier Tamayo Jaramillo, Tratado de Responsabilidad Civil, Tomo I. (Bogotá: Legis, 2017), 201. 
En cuanto a la capacidad, en materia de responsabilidad contractual, corresponde a la capacidad general para obligarse. A diferencia de la capacidad aquiliana que tiene reglas específicas previstas en el artículo 2219, el cual prescribe que "no son capaces de delito o cuasidelito los menores de siete años ni dementes". ${ }^{42}$ Según Abeliuk, esta diferenciación se justifica ya que es más fácil distinguir lo lícito de lo ilícito, que responder de los daños por el incumplimiento. ${ }^{43}$ Por último, es menester referirse a la prescripción. La acción de indemnización por incumplimiento de una obligación obedece a la regla general, es decir, diez años desde que la obligación se hizo exigible. ${ }^{44}$ En cambio, el artículo 2235 eiusdem prescribe una regla especial respecto de la acción por responsabilidad extracontractual: las acciones por un daño derivadas de la comisión de un delito o cuasidelito civil prescriben en cuatro años contados desde la perpetración del acto dañoso. ${ }^{45}$

Como se ha revisado, existen varios fundamentos de distinción dentro de este tópico. Entre ellos, las principales diferencias entre la responsabilidad contractual y extracontractual se centran en: (i) la mora; (ii) la culpa; su gradación y su presunción; (iii) la capacida; y (iv) la prescripción. Todos estos elementos diferenciadores son importantes —aunque no únicos- para el estudio de la responsabilidad aplicable al incumplimiento cuasicontractual, tomando como base la reglamentación del CC sobre los cuasicontratos. Sin embargo, el elemento diferenciador que corresponde estudiar a profundidad se da por el fundamento, el origen o la procedencia de cada una de las responsabilidades, lo cual se tratará en la siguiente sección.

\subsection{DisCuSIÓN SOBRE EL ALCANCE DE LA RESPONSABILIDAD CIVIL CONTRACTUAL Y EXTRACONTRACTUAL}

Existe un debate respecto del ámbito de cobertura, tanto de la responsabilidad contractual como de la aquiliana. Este disentimiento obedece al origen y alcance de cada tipo de régimen. En ese sentido, se discute si la primera abarca únicamente al incumplimiento de obligaciones contractuales en concreto, o si engloba al incumplimiento de obligaciones resultantes de un vínculo jurídico previo, independientemente de la fuente; $y$, en cuanto a la responsabilidad extracontractual, quedan dudas sobre si aquella comprende específicamente la comisión de delitos o cuasidelitos, o si se deriva de cualquier fuente obligacional que no sea un contrato.

Con respecto a la responsabilidad extracontractual, para Llambías es la que proviene de la infracción de cualquier otro deber jurídico en que se hubiere

2 Artículo 2219, CC.

43 Abeliuk, Las Obligaciones, 579.

44 Artículo 2415, CC.

45 Id. Artículo 2235. 
incurrido y en especial por los hechos ilícitos cometidos por ellos. ${ }^{46}$ Por tanto, este tipo de responsabilidad abarcará exclusivamente a los delitos y cuasidelitos. En cambio, Vodanovic considera que esta responsabilidad "es la que incide en un hecho delictuoso sin que exista un vínculo preexistente". ${ }^{47}$ En ese sentido coincide Corral Talciani apegándose a la tesis clásica de la responsabilidad extracontractual. En esta "no hay obligación previa entre las partes, sino que es justamente el hecho ilícito el que genera la obligación de resarcir". ${ }^{48}$ En concordancia con lo señalado por Vodanovic y Corral Talciani, la característica fundamental para saber si se está frente a la responsabilidad aquiliana, es el hecho de saber que no hay obligación preexistente entre la víctima y el deudor. Lo anterior va de la mano con lo señalado por Abeliuk con respecto a este tipo de responsabilidad: "el hecho ilícito da, en cambio, nacimiento a una obligación que antes de él no existía". ${ }^{49}$ A pesar de no ser incompatibles la tesis de Llambías con las de Vodanovic y Corral Talciani, no queda claro si la responsabilidad aquiliana tiene un carácter residual al de la responsabilidad contractual, o si es prescindible la comisión de un delito o cuasidelito, necesariamente.

Por otro lado, respecto a la responsabilidad contractual, Llambías indica que aquella proviene del incumplimiento de un contrato celebrado. ${ }^{50}$ De esa forma, este le otorga un alcance estricto que abarca exclusivamente el incumplimiento de una obligacion contractual preexistente. Abeliuk, Vodanovic y Corral Talciani asienten a la conceptualización anterior, pero la amplían manifestando que este tipo de responsabilidad supone la existencia de un vínculo jurídico obligacional previo - no necesariamente un contrato- ante cuya violación resulta el deber de indemnizar. ${ }^{51} \mathrm{El}$ alcance que la doctrina mayoritaria asigna a la responsabilidad contractual es extenso, sin limitarse estrictamente a una relación contractual previa. Basta con que haya una obligación anterior al daño — sea cual sea la fuente según esta teoría - para que se considere procedente la responsabilidad contractual.

En definitiva, si bien existen teorías que restringen el ámbito de la responsabilidad contractual y aquiliana, la opinión predominante sobre su alcance es explicada por Arturo Alessandri y Meza Barros:

[...] los autores entienden que la responsabilidad contractual supone una obligación anterior y se genera entre personas ligadas por un vínculo jurídico preexistente, a cuya violación sirve de sanción; en cambio, la responsabilidad delictual o cuasidelictual supone la ausencia de obligación previa, se produce entre personas

46 Llambías, Tratado de Derecho Civil, 62.

47 Vodanovic, Curso de Derecho Civil, 196.

48 Talciani, Lecciones de Responsabilidad Civil Extracontractual, 25.

49 Abeliuk, Las Obligaciones, 578.

50 Llambías, Tratado de Derecho Civil, 62.

51 Talciani, Lecciones de Responsabilidad Civil Extracontractual, 25. 
hasta entonces jurídicamente extrañas (por lo menos en cuanto al hecho de que deriva), y es ella la que crea la obligación de reparar el dańo. ${ }^{52}$

En concordancia con la tesis mayoritaria, ¿qué sucedería, entonces, con el incumplimiento cuasicontractual? Si se considera que la responsabilidad aquiliana tiene como presupuesto necesario la ausencia de un vínculo jurídico preexistente, el incumplimiento cuasicontractual no podría enmarcarse en esta categoría, dado que ya existe una relación jurídica previa al daño. Esto, por cuanto no se trata de personas jurídicamente extrañas, dado que existen obligaciones emanadas del cuasicontrato. En consecuencia, el incumplimiento cuasicontractual estaría regulado por el régimen de responsabilidad contractual, pues efectivamente hay un vínculo obligacional previo, cuyo incumplimiento merece ser sancionado.

\subsection{LA RESPONSABILIDAD CONTRACTUAL Y AQUILIANA EN LA JURISPRUDENCIA ECUATORIANA}

El criterio de los tribunales judiciales ecuatorianos ha evolucionado con cierto grado de uniformidad con relación al alcance de las responsabilidades. De esa manera, la Primera Sala de lo Civil y Mercantil de la Corte Suprema de Justicia en el caso Tito Yépez Jiménez c. World Vacation Wortion S.A. y Time Sharing S.A. en el año 2001, se limitó a citar al tratadista Arturo Alessandri Rodríguez al considerar el origen de cada tipo de responsabilidad materia de estudio. Primero, se refirió al alcance de la responsabilidad aquiliana:

La responsabilidad delictual o cuasidelictual civil proviene de un delito o cuasidelito civil, es decir, de un hecho ilícito, intencional o no, que ha inferido injuria o daño a la persona o propiedad de otro. Esta responsabilidad no deriva de la inejecución de una obligación preexistente; ninguna existe entre la víctima y el autor del daño [...] la responsabilidad delictual o cuasidelictual es, por lo mismo, fuente de obligaciones; con anterioridad no existía entre las partes ninguna obligación con la cual se relacione el hecho que la genera. ${ }^{53}$

De esta manera, se resaltó la procedencia de la responsabilidad extracontractual condicionada a la ausencia de un vínculo obligacional preexistente.

En cuanto a la responsabilidad contractual, se manifestó que aquella "supone una obligación anterior, se produce entre personas ligadas por un vínculo jurídico preexistente, a cuya violación sirve de sanción" ${ }^{54} \mathrm{El}$ alcance que se da a este tipo de responsabilidad presupone la existencia de una relación obli-

52 Alessandri, De la responsabilidad extracontractual, 35 y Meza Barros, Manual de Derecho Civil: 250.

53 Juicio No. 142-2001, párr. 11.

54 Ibid. 
gacional previa, sin limitarse exclusivamente al contrato en específico. Por consiguiente, bien podría incluirse en esta categoría el incumplimiento cuasicontractual.

Sin embargo, posteriormente, al analizar el caso concreto, el Tribunal restringe este tipo de responsabilidad a las obligaciones originadas de un vínculo contractual necesariamente, al señalar: "[e]l actor [...] confunde la naturaleza de la responsabilidad que nace de un cuasidelito, o sea extracontractual, con la responsabilidad contractual, que se origina en la celebración de un contrato o convención". ${ }^{55}$ Así, el Tribunal deja abierta la discusión sobre cuál es el criterio definitivo acerca del alcance de la responsabilidad contractual.

Posteriormente, la misma Corte Suprema de Justicia en el año 2005, adoptó la postura precedente al indicar que: "[e]n la responsabilidad contractual, el responsable y la víctima estaban ligados por un contrato, existía una obligación entre ellos, y por el incumplimiento de esa obligación el acreedor pide reparación al deudor" ${ }^{56}$ De esa forma, la Corte se inclina por la postura restrictiva de la responsabilidad contractual. En ese sentido, también se pronunció acerca de la responsabilidad aquiliana, reiterando la postura optada en el año 2001, resaltando el presupuesto de la necesaria carencia de un vínculo obligacional previo para que proceda este tipo de régimen.

Por último, en el año 2014, la Corte Nacional de Justicia confirmó el criterio adoptado por la ex Corte Suprema en el año 2005, cuya conclusión se relaciona a la procedencia de la responsabilidad civil de manera genérica, al establecer: "[...] tal responsabilidad proviene de la violación de un contrato, de la comisión de un delito o cuasidelito civil o de un delito o cuasidelito penal o de la ley". ${ }^{57}$ Cabe mencionar que los tribunales judiciales no han basado sus conclusiones en los preceptos del CC al momento de analizar el alcance de los regímenes de responsabilidad contractual y aquiliana, puesto que en más de una ocasión se han limitado a citar doctrina únicamente. De igual manera se observa que la jurisprudencia ecuatoriana no ha otorgado una respuesta a la pregunta que nos ocupa: ¿cuál es el régimen aplicable en materia de responsabilidad ante daños resultantes del incumplimiento cuasicontractual? Puesto que, el consenso jurisprudencial, restringe la responsabilidad contractual a la existencia de un contrato previo y hace procedente a la responsabilidad aquiliana únicamente ante la comisión de delitos y cuasidelitos civiles. De esa manera, el incumplimiento cuasicontractual no se enmarca en ninguna de las dos hipótesis, existiendo un vacío en cuanto al régimen aplicable.

55 Juicio No. 142-2001, párr. 12.

56 Juicio No. 56-2004, párr. 5.

57 Juicio No. 17711-2014-0540, párr. 6.3. 


\subsection{UN ACERCAMIENTO HACIA LA RESPONSABILIDAD CUASICONTRACTUAL}

Algunos autores han propuesto teorías con el objetivo de dar por terminada la discusión acerca del ámbito de cobertura de la responsabilidad contractual y aquiliana, para de esa manera determinar el régimen aplicable al incumplimiento de obligaciones cuasicontractuales. $\mathrm{Al}$ respecto, se ha discutido la tesis del "derecho común en materia de responsabilidad", mencionada por Luis Claro Solar, Abeliuk y Corral Talciani, la cual prevé que la regla general en cuanto a la responsabilidad son las reglas de la contractual.

Adriano de Cupis señala que "[...] en la denominación de daño contractual debe considerarse todo incumplimiento de una obligación preexistente, aunque no sea de origen contractual".$^{58}$ Sobre la base de esta tesis, el incumplimiento de las obligaciones cuasicontractuales se rige por los principios y criterios normativos que regulan la responsabilidad contractual. ${ }^{59}$

Esta teoría se sustenta en el CC chileno -siendo muy similar al ecuatoriano-, específicamente en los artículos que prescriben la gravedad de la culpa en obligaciones legales y cuasicontractuales. ${ }^{60}$ Como resultado de la aplicación de esta teoría, la responsabilidad aquiliana constituiría la excepción. Por tanto, al ser la responsabilidad contractual la regla general, la vulneración de obligaciones cuasicontractuales se encasilla en esta categoría.

En ese sentido coinciden Alessandri Rodríguez y Velásquez Posada. Por un lado, Alessandri sustenta esta tesis mencionando explícitamente la categoría a la que pertenece el incumplimiento cuasicontractual: "[l]a infracción de una obligación contractual, cuasicontractual o legal da origen a la responsabilidad contractual únicamente: el acreedor cuyo deudor viola su obligación no podría demandarle perjuicios por esta violación con arreglo a los artículos $2314^{61}$ y siguientes del Código Civil”. ${ }^{62}$ Por su parte, Velásquez expone otro razonamiento, no obstante que llega a la misma conclusión que Alessandri:

Los deberes jurídicos pueden ser genéricos o concretos. Si se considera que el daño es consecuencia de la violación de un deber jurídico concreto, la responsab-

58 Adriano De Cupis, trad. Martínez Sarrión, El daño. Teoría general de la responsabilidad civil (Barcelona: Editorial Bosch, 1975), 133.

59 Talciani, Lecciones de Responsabilidad Civil Extracontractual, 40.

60 Art. 2288. Debe en consecuencia emplear en la gestión los cuidados de un buen padre de familia; pero su responsabilidad podrá ser mayor o menor en razón de las circunstancias que le hayan determinado a la gestión. Si se ha hecho cargo de ella para salvar de un peligro inminente los intereses ajenos, sólo es responsable del dolo o de la culpa grave; y si ha tomado voluntariamente la gestión, es responsable hasta de la culpa leve; salvo que se haya ofrecido a ella, impidiendo que otros lo hiciesen, pues en este caso responderá de toda culpa.

61 Este artículo equivale al artículo 2214 del Código Civil ecuatoriano: "El que ha cometido un delito o cuasidelito que ha inferido dańo a otro, está obligado a la indemnización; sin perjuicio de la pena que le impongan las leyes por el delito o cuasidelito". Referente a la responsabilidad cuasicontractual regulada por dicho cuerpo normativo.

62 Alessandri, De la responsabilidad extracontractual, 45. 
ilidad será contractual, si es de la violación o incumplimiento de un deber genérico (abstracto), la responsabilidad será extracontractual. Esta concepción implica que la responsabilidad contractual no nace exclusivamente del incumplimiento de obligaciones surgidas en una relación contractual, sino también en el incumplimiento de obligaciones nacidas de actos unilaterales como los cuasicontratos o de obligaciones legales, como ocurre cuando un mandatario excede los límites del mandato. ${ }^{63}$

De esa manera, quedan claras las posturas que circunscriben al quebrantamiento de una obligación surgida por un cuasicontrato dentro de la regulación del régimen de responsabilidad contractual. Por cuanto: (i) aquella es la regla general en materia de aplicación de responsabilidades; y (ii) las obligaciones cuasicontractuales son en sí deberes jurídicos concretos en concordancia con lo seńalado por Velásquez, siendo su incumplimiento un presupuesto para la aplicación de la responsabilidad contractual.

Por otro lado, en la doctrina francesa prevalece la tesis contraria, en la que la responsabilidad aquiliana es la regla general. ${ }^{64} \mathrm{La}$ razón de ser de esta teoría se basa en la estructura y contenido del CC francés. El Libro III contiene, por un lado, el Título III, donde se regulan las obligaciones contractuales y la responsabilidad contractual, en el capítulo III, sección 4: "[d]e las indemnizaciones por daños y perjuicios derivadas del incumplimiento de la obligación". En cambio, el Título IV del mismo Libro reglamenta lo concerniente a "las obligaciones que se contraen sin convención", respecto de la responsabilidad aquiliana. De ese modo, la normativa francesa deja en expreso la limitación de la responsabilidad contractual a las obligaciones contractuales y la amplitud de la responsabilidad aquiliana, la cual abarca a toda obligación no convencional. Por consiguiente, es entendible que en Francia prevalezca la idea de que el régimen extracontractual constituya la responsabilidad común, dado que el Código francés es cuidadoso y prolijo al regular y diferenciar el alcance de cada régimen de responsabilidad.

Lo anterior, no ocurre en lo prescrito por el CC espańol ni el chileno y, por ende, tampoco en lo normado por el CC ecuatoriano, pues en ellos se regula la responsabilidad contractual aplicada abstractamente a las relaciones obligacionales, sin referencia alguna a su fuente. $\mathrm{Al}$ respecto, el CC español prescribe en el Libro Cuarto: "De las obligaciones y contratos", bajo el Capítulo 2 "de la naturaleza y efecto de las obligaciones" y, en concreto, el artículo 1101 señala que, "[q]uedan sujetos a la indemnización de los daños y perjuicios causados los que en el cumplimiento de sus obligaciones incurrieren en dolo, negligencia o morosidad, y los que de cualquier modo contravinieren al tenor de aquellas". ${ }^{65}$ En base a esta reglamentación, la regulación pertinente a la res-

63 Velásquez, Responsabilidad Civil Extracontractual, 49.

64 Mazeaud, "Responsabilité", 551.

65 Artículo 1101, Código Civil de Espańa. Gaceta de Madrid No. 206. 27 de julio de 1889. 
ponsabilidad contractual resultaría ser aplicable de manera genérica. En este sentido, la situación bajo el CC chileno es parecida ${ }^{66} \mathrm{y}$, en consecuencia, tiene igual tratamiento bajo la normativa ecuatoriana, la cual se analizará a fondo con posterioridad.

Sobre la base de esta idea, Díez-Picazo indica la tendencia existente hacia la redefinición de la responsabilidad contractual, donde cabe el supuesto de incumplimiento cuasicontractual, ya que se pretende extender el campo de aplicación de la responsabilidad contractual "englobando en ella los dańos que puedan surgir como consecuencia del desarrollo de obligaciones de carácter no contractual, pero previamente existentes entre las partes como vínculos jurídicos, por ejemplo, el condominio". ${ }^{67}$

Es por este motivo que existe la posibilidad de que nuestro ordenamiento jurídico se adapte a la teoría chilena y española expuesta por: Alessandri, Velásquez Posada, Corral Talciani y Díez-Picazo. Sin embargo, antes de adelantar este criterio, es importante analizar específica y detenidamente las normas que regulan la responsabilidad civil y los cuasicontratos para determinar si verdaderamente es aplicable la teoría expuesta, en Ecuador.

\section{LA RESPONSABILIDAD CIVIL APLICABLE ANTE EL INCUMPLIMIENTO CUASICONTRACTUAL SEGÚN LA NORMATIVA ECUATORIANA}

\subsection{Indicios del Código Civil}

En esta sección se realizará un recorrido por las normas del CC, con el objetivo de identificar el tipo de responsabilidad aplicable al incumplimiento cuasicontractual, comenzando por el análisis textual previsto para la reglamentación de la dualidad de regímenes de la responsabilidad civil. En ese sentido, el Título XII prescribe el "Efecto de las Obligaciones", el cual regula la responsabilidad contractual. Sin embargo, como se indicó, la normativa nacional no ha restringido los efectos establecidos en esta sección para las obligaciones contractuales en concreto, como lo han hecho otros ordenamientos jurídicos, como es el caso del CC francés. De manera que no se puede asumir vagamente que lo establecido en esta sección no sea pertinente a la responsabilidad contractual. Únicamente se subsume a obligaciones originadas por un vínculo contractual, puesto que de la literalidad del Título XII se desprende una reglamentación amplia para las obligaciones de manera genérica.

66 Ver, Código Civil de la República de Chile: Libro Cuarto, Título XII Del efecto de las obligaciones, Ley 21264. 2000, modificado por última vez el 11 de septiembre del 2020.

67 Díez-Picazo, Derecho de Daños, 264. 
Por otro lado, el Título XXXIII prescribe "De los delitos y cuasidelitos", atendiendo a la responsabilidad extracontractual o aquiliana. El artículo inicial de este Título establece: "[e]l que ha cometido un delito o cuasidelito que ha inferido daño a otro, está obligado a la Indemnización [...]". ${ }^{68}$ De lo anterior, se evidencia la restricción de la aplicación de este tipo de responsabilidad a la comisión de delitos y cuasidelitos civiles únicamente. Aquello descarta el carácter residual que ciertos doctrinarios suelen atribuir a la responsabilidad aquiliana, pues, de acuerdo con la norma, no cabe interpretar la aplicación de este régimen a toda obligación que no sea contractual. De acuerdo con una revisión textual de la estructura de la dualidad de responsabilidades, se puede concluir, de manera inicial, que el incumplimiento cuasicontractual parecería estar normado bajo las reglas del Título XII, atendiendo a la responsabilidad contractual.

Otro fundamento previamente mencionado que distingue a ambas responsabilidades, es la capacidad. El artículo 2219 del CC prescribe reglas de capacidad especiales aplicables a la responsabilidad aquiliana. De esa manera, este artículo seńala: "[n]o son capaces de delito o cuasidelito [...]", ${ }^{69}$ comprobando nuevamente que la normativa prescrita para la responsabilidad civil extracontractual es aplicable y restringida exclusivamente a la comisión de delitos y cuasidelitos, no siendo posible su empleo a otro tipo de obligaciones emanadas de una fuente distinta.

$\mathrm{Al}$ efectuar un acercamiento hacia los elementos de la responsabilidad, cabe hacer el análisis del hecho antijurídico. El CC no prescribe expresamente este elemento; sin embargo, los artículos 2214 y 1572 permiten inferir cuál es el hecho antijurídico en cada tipo de responsabilidad. Respecto al artículo 2214, queda claro que el hecho que da paso a la responsabilidad aquiliana es la comisión del delito o cuasidelito. ${ }^{70}$ Con relación al artículo 1572 , se entiende que el hecho antijurídico de la responsabilidad contractual es el incumplimiento de la obligación, siendo la mora la situación que otorga el derecho de reclamar esta responsabilidad, en concordancia con el artículo 1573: "[s]e debe la indemnización de perjuicios desde que el deudor se ha constituido en mora, o, si la obligación es de no hacer, desde el momento de la contravención". ${ }^{71}$

Si bien se podría considerar que el supuesto de ilicitud en el incumplimiento del contrato resultaría diferente al derivado de un cuasicontrato, esto sería incorrecto, pues los elementos del hecho ilícito contractual pueden ser aplicados y/o contrarrestados en el incumplimiento cuasicontractual. Estos elementos son: (i) un contrato válido; (ii) culpa; y (iii) mora. ${ }^{72} \mathrm{La}$ exigencia de

72 Jorge Bustamante Alsina, Teoría General de la Responsabilidad Civil (Buenos Aires: Abeledo-Perrot, 1997), 95. 
un contrato válido radica en la necesidad de justificar la procedencia y fuente de las obligaciones que son incumplidas. Así lo entiende Bustamante cuando señala que "[e]l contrato debe ser válido, si así no fuera no habría obligación alguna que tuviese su fuente en el mismo" ${ }^{73}$ Este requisito no va a ser necesario para respaldar la antijuridicidad en el incumplimiento cuasicontractual, dado que las obligaciones de él derivadas son válidas por el hecho de estar prescritas como tales por la ley, ante la ocurrencia del hecho voluntario de una de las partes. En cuanto a la culpa, Bustamante considera que "[l]a culpa en el incumplimiento contractual se manifiesta por el dańo causado al acreedor con negligencia o imprudencia en la observancia del específico deber jurídico establecido". ${ }^{74}$ De esa forma, este elemento se adapta plenamente al supuesto cuasicontractual, dado que será suficiente la exteriorización del daño derivado del incumplimiento para que medie la culpa.

Respecto a la mora, el CC prescribe su aplicación de la siguiente manera:

Art. 1567.- El deudor está en mora:

1. Cuando no ha cumplido la obligación dentro del término estipulado, salvo que la ley, en casos especiales, exija que se requiera al deudor para constituirle en mora; 2. Cuando la cosa no ha podido ser dada o ejecutada sino dentro de cierto espacio de tiempo, y el deudor lo ha dejado pasar sin darla o ejecutarla; y 3. En los demás casos, cuando el deudor ha sido judicialmente reconvenido por el acreedor. ${ }^{75}$

De esa manera cabe preguntarse, ¿hay mora en las obligaciones cuasicontractuales? Claramente sí. En primer lugar, en una relación en donde medie un cuasicontrato hay necesariamente un deudor. En segundo lugar, el Código no limita la procedencia de la mora a ningún tipo especial de obligaciones con relación a su fuente, y al ser las de un cuasicontrato: positivas, de dar y hacer como se observó en el subtítulo "4.3. Hipótesis de incumplimiento cuasicontractual", su naturaleza y la susceptibilidad de aquellas de ser incumplidas tienen como consecuencia que el elemento de la mora pueda estar presente. En tercer lugar, al subsumir el incumplimiento cuasicontractual al artículo citado, el deudor de una obligación derivada de un cuasicontrato incurrirá en mora, por regla general, al momento del requerimiento judicial por parte del acreedor. Por consiguiente, el quebrantamiento de una obligación cuasicontractual es efectivamente el hecho antijurídico y la mora el supuesto previo para el reclamo de la responsabilidad, coincidiendo una vez más en uno de los elementos de la responsabilidad contractual.

Como se indicó previamente, otro de los componentes que diferencia a la 
dualidad de regímenes, es la culpa y su gradación. Al respecto, la culpa se define doctrinariamente como "la falta de diligencia o cuidado en la ejecución de un hecho o en el cumplimiento de una obligación. En el primer caso, la culpa es extracontractual, delictual o aquiliana, y en el segundo es contractual". ${ }^{76}$ El CC ecuatoriano no ha definido a la culpa en expreso, limitándose a hacer una triple gradación entre: grave, leve y levísima a propósito de la culpa contractual $;{ }^{77}$ no obstante, esta diferenciación no aplica en materia delictual. Es respecto a la culpa y su gradación donde se encuentra el mayor indicio de aplicación de la responsabilidad contractual a las obligaciones cuasicontractuales. Por cuanto, los artículos 2188 y 2208 del Código id. admiten la gradación de culpas en la agencia oficiosa y la comunidad respectivamente:

Art. 2188.- Debe, en consecuencia, emplear en la gestión los cuidados de un buen padre de familia; pero su responsabilidad podrá ser mayor o menor en razón de las circunstancias que le hayan determinado a la gestión.

Si se ha hecho cargo de ella para salvar de un peligro inminente los intereses ajenos, sólo es responsable del dolo o de la culpa grave; y si ha tomado voluntariamente la gestión, es responsable hasta de la culpa leve; salvo que se haya ofrecido a tomarla, impidiendo que otros la tomasen; pues en este caso responderá de toda culpa. ${ }^{78}$

Art. 2208.- Cada comunero debe a la comunidad lo que saca de ella, inclusos los intereses corrientes de los dineros comunes que hubiese empleado en sus negocios particulares; y es responsable hasta de la culpa leve por los daños que hubiese causado en las cosas y negocios comunes. ${ }^{79}$

En consecuencia, se evidencia una vez más la aplicación de preceptos propios de la responsabilidad contractual a las relaciones cuasicontractuales.

\section{ConClusión}

La discusión doctrinaria que se enmarca alrededor del alcance de la división clásica de responsabilidades ha sido extensa y reñida. Asimismo, este debate ha dejado un vacío legal que se encuentra no solo en el ordenamiento jurídico nacional, sino en el sistema como tal. Como se ha señalado, han pasado décadas y la jurisprudencia no ha podido otorgar una opinión firme y definitiva que resuelva esta discusión, puesto que el razonamiento utilizado para alcanzar su criterio no ha incluido un análisis concreto de la norma que permita justificar su postura en conjunto con los preceptos del CC. Por otro lado, a pesar de que se ha llegado a una especie de consenso doctrinario y se ha alcanzado una opinión mayoritaria acerca de la delimitación de la responsabilidad

\footnotetext{
6 Abeliuk, Las Obligaciones, 131.

77 Artículo 1563, CC.

78 Id. Artículo 2188.

79 Id. Artículo 2208.
} 
contractual y extracontractual, la escasa aplicación práctica de esos preceptos hace difícil la tarea de determinar la responsabilidad aplicable al incumplimiento cuasicontractual.

Por su parte, el CC tampoco regula de manera explícita la amplitud de ambas instituciones, mucho menos los elementos constitutivos de cada una, por lo que no otorga una solución en concreto acerca de la problemática expuesta. Sin embargo, es posible inferirla, pues el Código ha dado luces que guían hacia la respuesta que se busca en el presente trabajo. En ese sentido, se han encontrado en la normativa distintos elementos propios de la responsabilidad contractual que resultan aplicables a las obligaciones cuasicontractuales, entre los que se ha visto: (i) el hecho antijurídico; (ii) la constitución en mora de las obligaciones cuasicontractuales; (iii) las reglas de la capacidad; y, (iv) la gradación de la culpa en los cuasicontratos. Además, también se tomó en cuenta la literalidad: tanto en la estructura, como en la normativa que regula el régimen contractual y extracontractual, donde se determinó que, bajo nuestro sistema, la responsabilidad contractual es de aplicación general y abarca los dańos provenientes de cualquier incumplimiento, sea o no convencional. Esta premisa permite llegar a la conclusión de que ante daños resultantes del incumplimiento de un cuasicontrato se deben aplicar las reglas de la responsabilidad contractual. Posiblemente esto ocurre por la irónica similitud entre ambas figuras, a pesar de su criterio distintivo fundamental: la intención. Lo expuesto es concordante con las teorías modernas de responsabilidad que sugieren que el régimen común es el contractual, junto con la propuesta de una interpretación y aplicación extensiva de la responsabilidad contractual a las obligaciones cuasicontractuales y legales, tal como lo sugiere Díez-Picazo, ${ }^{80}$ pues, de acuerdo con lo analizado, estas teorías encajan completamente en nuestro ordenamiento jurídico.

Desde luego, esta posición deberá ser complementada con el análisis jurisprudencial ecuatoriano, respecto del ámbito de cobertura que abarca; tanto la responsabilidad contractual como la aquiliana, de manera que se pueda avanzar y determinar el tipo de régimen aplicable que se deriva del incumplimiento cuasicontractual. Esto, con el propósito de dejar un precedente que otorgue la seguridad jurídica a las cotidianas relaciones cuasicontractuales, pues la interpretación realizada de los preceptos del CC, junto con la coincidente opinión doctrinaria mayoritaria, necesitan de un sustento firme y de trascendencia jurídica para que pueda ser aplicado con certeza en la práctica. 